\title{
Interleukin-2-Inducible T-Cell Kinase (ITK) Deficiency - Clinical and Molecular Aspects
}

\author{
Sujal Ghosh • Kirsten Bienemann • Kaan Boztug • \\ Arndt Borkhardt
}

Received: 21 July 2014 / Accepted: 7 October 2014 /Published online: 24 October 2014

(C) The Author(s) 2014. This article is published with open access at Springerlink.com

\begin{abstract}
In patients with underlying immunodeficiency, Epstein-Barr virus (EBV) may lead to severe immune dysregulation manifesting as fatal mononucleosis, lymphoma, lymphoproliferative disease (LPD), lymphomatoid granulomatosis, hemophagocytic lymphohistiocytosis (HLH) and dysgammaglobulinemia. Several newly discovered primary immunodeficiencies (STK4, CD27, MAGT1, CORO1A) have been described in recent years; our group and collaborators were able to reveal the pathogenicity of mutations in the Interleukin-2-inducible T-cell Kinase (ITK) in a cohort of nine patients with most patients presenting with massive EBV Bcell lymphoproliferation. This review summarizes the clinical and immunological findings in these patients. Moreover, we describe the functional consequences of the mutations and draw comparisons with the extensively investigated function of ITK in vitro and in the murine model.
\end{abstract}

Keywords Epstein-Barr virus (EBV) $\cdot$ IL-2 inducible kinase (ITK) deficiency

S. Ghosh $\cdot$ K. Bienemann $\cdot$ A. Borkhardt $(\triangle)$

Department of Pediatric Oncology, Hematology and Clinical Immunology, Medical Faculty, Center of Child and Adolescent Health, Heinrich-Heine-University, Moorenstraße 5, 40225 Duesseldorf, Germany

e-mail: arndt.borkhardt@med.uni-duesseldorf.de

S. Ghosh

Institute of Child Health, Molecular and Cellular Immunology Section, UCL Institute of Child Health, 30 Guilford Street, London WC1N 1EH, UK

\section{K. Boztug}

CeMM Research Center for Molecular Medicine of the Austrian Academy of Sciences, Department of Paediatrics and Adolescent Medicine, Medical University of Vienna, Vienna 1090, Vienna, Austria

\section{Background}

Epstein-Barr virus (EBV), being one of the most common viruses in humans, is best known to cause infectious mononucleosis. In patients with underlying immunodeficiency, EBV may lead to severe immune dysregulation manifesting as fatal mononucleosis, Hodgkin and NonHodgkin lymphoma, lymphoproliferative disease (LPD), lymphomatoid granulomatosis, hemophagocytic lymphohistiocytosis (HLH) and dysgammaglobulinemia [1]. Patients, who harbor alterations in genes coding for proteins of the lymphocytic cytotoxic pathway, $\mathrm{T}$ cell signaling or T-B cell interaction, may present with EBV associated disease [2]. Mutations in genes of the cytotoxic pathway (e.g. PRF1) can lead to hemophagocytic lymphohistiocytosis (HLH) after an infectious trigger, terming these diseases collectively as hemophagocytic syndromes [3, 4]. Furthermore the quite heterogeneous group of combined immunodeficiencies (leaky or atypical SCID) with defects affecting antigen receptor recombination (e.g. hypomorphic mutations in $R A G 1 / 2)$ and some distinct genes of $\mathrm{T}$ cell signaling (e.g. in SH2D1A, XIAP) can lead to EBV associated disease due to immune dysregulation, notably lymphoproliferation $[5,6]$. However, EBV pathophysiology varies in each of these diseases.

Several newly discovered primary immunodeficiencies with EBV lymphoproliferation (STK4, CD27, MAGT1, Coronin-1A deficiency) have been described in the last few years [7-11]; our group and collaborators were able to reveal the pathogenicity of mutations in the Interleukin 2-inducible T-cell kinase (ITK) gene in a cohort of eight patients all presenting with massive EBV B-cell lymphoproliferation [12-15]. One further patient with recurrent infections and CD4 lymphopenia, but without lymphoproliferation was just 
recently discovered [16]. Hence, we will briefly summarize the clinical and immunological findings in patients suffering from ITK deficiency and draw comparisons with the extensively investigated function of ITK in vitro and in the murine model.

\section{Clinical Presentation}

In 2009, we described two sisters of consanguineous Turkish descent with EBV lymphoproliferation [12]. The older sister (at the age of 6 years) presented with severe candida stomatitis, pneumocystis jirovici pneumonia, pleural and pericardial effusion, hepatosplenomegaly, cytopenia and progressive hypogammaglobulinemia. A biopsy of an axillary lymph node revealed oligoclonal polymorphic B cell lymphoproliferation of type II latency. Despite repeated courses of Rituximab and partial resolution of clinical symptoms $1 \frac{1}{2}$ year later the girl developed Hodgkin's lymphoma. Successfully treated according to standard chemotherapy protocol, T cells unfortunately were continuously declining and the girl died from respiratory failure after acquiring pneumocystis pneumonia at the age of $101 / 2$ years. The younger sister developed pancytopenia, hepatosplenomegaly, abdominal lymphadenopathy, ascites and pleural effusions due to impaired liver function. EBV associated Hodgkin lymphoma was detected in an inguinal lymph node biopsy; as the clinical situation deteriorated remission could not be achieved and she received haploidentical peripheral blood stem cell transplantation (SCT); unfortunately she died of ischemic brain injury following airway obstruction and cardiac arrest in aplasia. We performed genome-wide linkage analysis with eight family members identifying a region at 5q31-34 that segregated with the disease. Subsequent analysis of candidate genes led to the causative homozygous $\mathrm{R} 335 \mathrm{~W}$ mutation in the $\mathrm{SH} 2$ domain of ITK. Till now we have gathered information on further six patients presenting primarily with massive EBV B-cell lymphoproliferation further progressing to full malignant Hodgkin lymphoma in some cases: three patients were within a family of Palestinian origin [15]; and a total of three single individuals from Iran [14], India and Morocco. Patients with lymphoproliferative disease / Hodgkin lymphoma manifested between 3 and 13 years of age with fever, lymphadenopathy, hepatosplenomegaly and EBV viremia; additional viral infections in some patients included CMV and severe varicella infections indicating a general $\mathrm{T}$ cell deficiency. Given severe immune dysregulation, three patients developed autoimmune phenomena (cytopenia, nephritis and thyroiditis); two patients developed HLH. Pulmonary involvement with large interstitial nodules was observed in the majority of patients, as it is known from other EBV-related pathologies; remarkably, extensive pulmonary infiltration of EBV-LPD leading to respiratory distress was the only major primary manifestation in one patient [14]. A ninth ITK deficient patient has just recently been discovered. Interestingly the 18 year-old male Turkish patient of consanguineous background suffered from recurrent progressive pulmonary infections, but no lymphoproliferation so far. Please refer to Table 1 for further details.

\section{Immune Phenotype, Viral Burden and Lymphoproliferation}

Common immunological features in ITK deficient patients are progressive hypogammaglobulinemia and beside global lymphopenia, a progressive loss of CD4+ T cells. Notably, we observe a declining proportion of naive CD45RA $+\mathrm{CD} 4+\mathrm{T}$ cells. After gating on $\mathrm{CD} 3+\mathrm{T}$ cells, NKT cells are determined as TCR Vbeta11 and TCR Valpha24 double-positive cells [17]. As seen in other syndromes susceptible to EBV-LPD (e.g. patients with SAP, XIAP, CD27 and Coronin-1A deficiency) NKT cells are severely reduced in the peripheral blood of ITK deficient patients [18]; hence a critical role has been postulated for NKT cells in the response to EBV infection [19]. Patients with EBV-LPD show a rather high EBV viremia though the observed peak viral load in the eight reported patients was quite heterogeneous $\left(10^{\wedge} 4-10^{\wedge} 8\right.$ copies/ $\mu \mathrm{g}$ DNA). As the serological phenotype at the time of manifestation differs among the patients, it is only hypothetical to predict the duration between primary infection and clinical immune dysregulation. We did not observe EBV-VCA-IgM in any ITK deficient person; though negative EBNA1-IgG in the first patient could suggest a rather short latency period. No EBV-VCA-IgG seronegative symptomatic EBV-LPD patient has been identified so far (as has been documented in SAP deficiency), leading to the assumption that EBV infection might be essential to cause immune dysregulation in particular LPD, lymphoma and autoimmunity in ITK deficiency. However, the ninth patient lacking EBV-LPD shows a seronegative EBV-VCA status, though revealing a low level of viremia (10^3 copies/ $\mu \mathrm{g}$ DNA). In any case, the early detection and watchful clinical monitoring of ITK deficient patients prior to their first encounter to EBV would be highly desirable.

\section{Treatment and Outcome}

Patients manifested between 3 and 13 years of age. Six out of eight described patients died between 1 and 15 years after primary manifestation of ITK deficiency, five of them within 2 years after the first symptoms appeared. Given the fact, that treatment of EBV-LPD has been best investigated in posttransplant lymphoproliferative disorder (PTLD) patients with a rather type III latency phenotype [20], experience to treat EBV-LPD in primary immunodeficiencies is limited and case- 


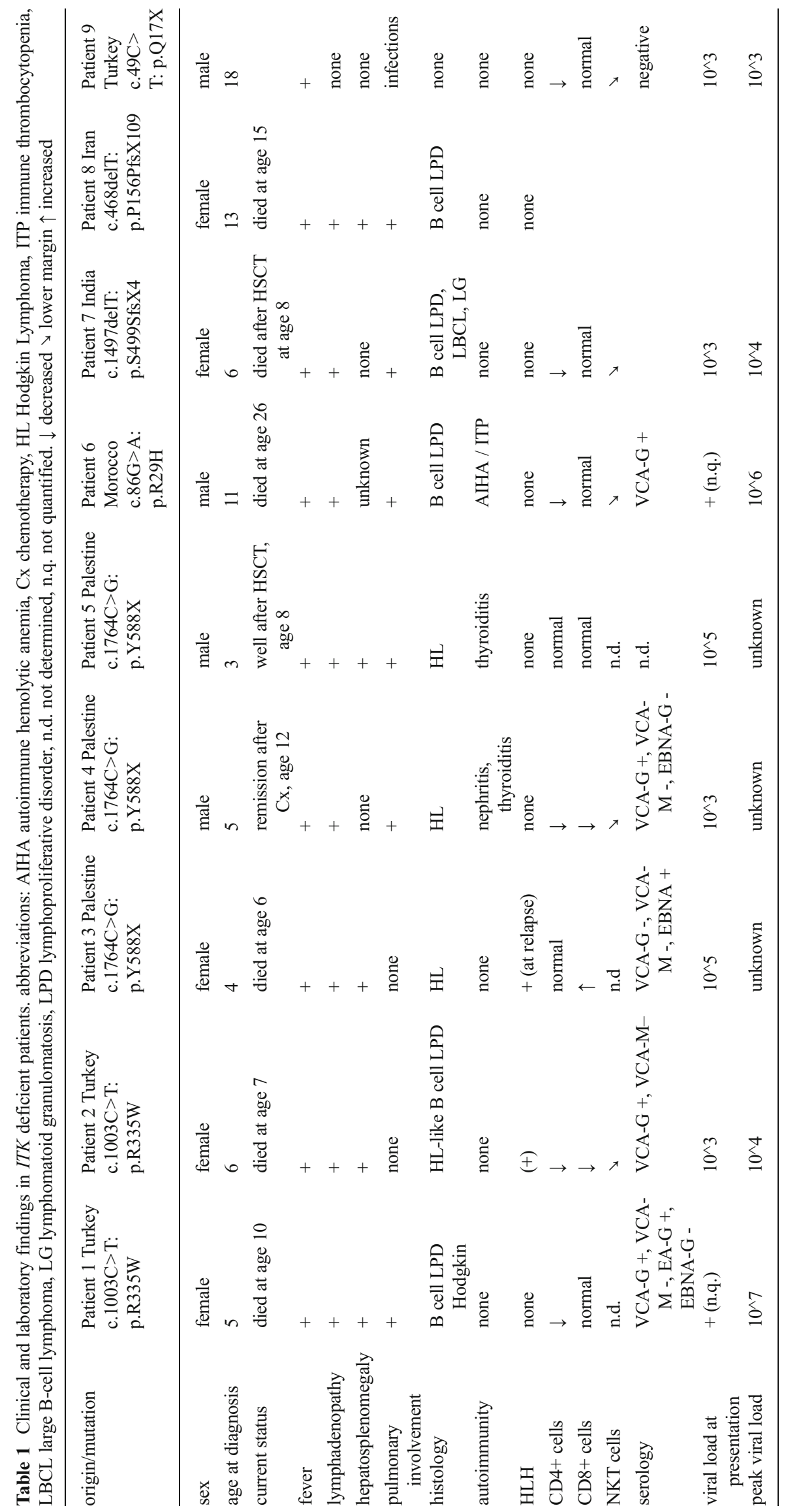


based. Rituximab led to clinical improvement in some ITK deficient patients, while steroids did not show any substantial benefit. However, susceptibility to infections and viremia due to $\mathrm{T}$ cell depletion and hypogammaglobulinemia is hardly controlled by antivirals or antibiotics. IgG substitution might be helpful, but however, increasing autoimmunity (nephritis, cytopenia) and Hodgkin lymphoma with the need of chemotherapy and potentially irradiation increase the risk of a fatal outcome. Remarkably, two patients of Palestine origin are alive [15]. While one is in remission after chemotherapy in Hodgkin lymphoma, the other one received a matched sibling bone marrow graft. One girl of Indian origin died after hematopoetic stem cell transplantation due to severe graftversus-host disease, so at this moment it will remain unclear whether the outcome depends on the nature of disease, pathogenicity of individual mutations or other circumstances unless a bigger cohort is investigated. At least each patient should be evaluated for potential HSCT.

\section{Interleukin-2-Inducible T-Cell Kinase (ITK)}

TEC family kinases comprises five members in mammals namely Bruton agammaglobulinemia tyrosine kinase (BTK), TXK tyrosine kinase (TXK, also RLK), BMX non-receptor tyrosine kinase (BMX, also ETK), tec protein tyrosine kinase (TEC) and Interleukin-2-inducible T-cell kinase (ITK, also LYK) [21]. All proteins function as non-receptor proteintyrosine kinases in the development and signaling in the lymphoid lineage. X-linked (Bruton's) agammaglobulinemia, as one of the very first detected primary immunodeficiencies was described in 1952 [22]; the discovery of the corresponding gene happened approximately 40 years later, leading to deep molecular insight into the role of BTK in B cell commitment [23]; however studies on ITK deficiency in mice and in vitro were conducted long before the first patient was discovered in 2009. Notably, patients with peripheral T cell lymphoma had been found with translocations of ITK with the SYK gene and subsequent fusion proteins [24].

The ITK gene encompasses a region of $112 \mathrm{~kb}$ and 17 exons on chromosome $5 q$ and encodes 620 amino acids of a $71 \mathrm{kDa}$ protein. Like BTK, it consists of a pleckstrin homology $(\mathrm{PH})$ domain at the N-terminus, a Tec homology (TH) domain; a Src homology 3 (SH3) domain; a Src homology 2 (SH2) domain and a catalytic kinase domain at the C-terminus [25]. In the context of adaptive immune response in $\mathrm{T}$ and NKT cells antigen presenting cells activate the T cell receptor. Subsequently a series of phosphorylation recruits ITK (which is bound through its pleckstrin homology domain to phosphatidylinositol monophosphates) to the cell membrane, where it is phosphorylated by LCK enhancing autophosphorylation and full activation. ITK itself phosphorylates PLCG1, which subsequent leads to the cleavage of its substrates.
Further downstream of this pathway, the endoplasmic reticulum releases calcium in the cytoplasm and the nuclear activator of activated T-cells (NFAT) is translocated into the nucleus for transcriptional activity for further lymphokine production, $\mathrm{T}$ cell proliferation and differentiation. Among the six observed pedigrees (nine individuals) two families harbored mutations in the kinase, other three pedigrees had mutations in the $\mathrm{SH} 2$ and $\mathrm{PH}$ domain. In one patient a deletion led to a truncated $\mathrm{SH} 2$ and deleted kinase domain. Interestingly, in $B T K$, homologous mutations have been reported to cause $\mathrm{X}$ linked agammaglobulinemia and the observed mutations in our eight patients have mutations in corresponding BTK residues indicating similar structural alterations [13].

Our group did comprehensive studies in transformed Herpesvirus samiri (HVS) cell lines to characterize these mutations and analyze functional consequences. Most mutations did not dramatically change mRNA levels of the ITK gene, however taking protein instability into mind, immunoblot analyses of endogenous ITK protein showed several protein variants. Only one patient showed abundance of mRNA levels likely due to nonsense-mediated mRNA decay after a premature stop codon in exon 14 in the kinase region. Protein halflife was determined by pulse-chase studies and showed significant reduced values compared to wild-type ITK. Calcium response was assayed by flux studies in transformed HVS patient $\mathrm{T}$ lymphocytes after CD3 antibody dependent TCR stimulation showing clearly reduced or nearly absent cytosolic release of calcium ions in most patients. TCR-mediated calcium mobilization was restored in murine $I t k-/-$ thymocytes after transduction of a wild type ITK construct [13].

\section{Itk -/- Murine Phenotype}

It is not elaborated how impaired ITK function changes T cell development. Most studies have been undertaken in the Itk -/mouse model with a BALB/c or C57BL/6 background. While, there are even differences in $T$ cell response among these two models it is ambitious to draw a genuine conclusion from mice to human.

In Itk -/- mice thymocyte development gives rise to an increased population of innate single positive CD8+ (CD8SP) thymocytes [26]. Itk -/- CD8SP thymocytes resemble antigen-experienced $\mathrm{T}$ cells showing a CD122+ CD44hiCXCR3+ phenotype with high levels of the transcription factor Eomesodermin (Eomes) and IFNy production upon stimulation. Furthermore splenocytes revealed less CD4 and CD8 expression with a rather mature effector phenotype $(\mathrm{CD} 44+\mathrm{CD} 62 \mathrm{~L}+)$, also showing differential transcriptional signatures with increased levels of Eomes and Tbet as also observed in peripheral CD8 cells of ITK deficient patients [27-31]. As observed in humans, NKT cell development and function is impaired and peripheral survival is reduced [32]. 


\section{TH1 Skewing}

The current model (in mice and human) of naive CD4 cell differentiation encompasses further maturation to Th1, Th2, Th17, Treg and Tfh cells, not including further more subsets to follow. However, most in vitro and in vivo murine studies addressing the molecular defects of Itk $-/-$ CD4 T cells did focus on the Th1/Th2 paradigm giving some evidence that ITK might be responsible for a proper Th2 response [25]. Following TCR stimulation ITK deficient $\mathrm{T}$ cells show decreased proliferation and effector cytokine production. In addition to reduced intracellular calcium release, which is shown in human as in mice, an altered NFAT nuclear translocation gives evidence of the biochemical disturbance [33-35]. Itk $-/-$ mice have decreased CD4 T cell numbers in the thymus and periphery [26]. Though, ITK seems to be dispensable for general TCR signaling (otherwise the clinical presentation would be more severe), several in-vivo studies of parasite infection in Itk $-/-$ mice indicate a role for ITK in Th2 response (see Table 2).

Itk $-/-$ mice showed poor granulomatous responses when challenged with Schistosoma mansoni eggs, a Th2 response inducing helminth [36]. Beside a marked reduction of size of granuloma and draining lymph nodes, IL-4, IL-5 and IL-10 production was decreased compared to $S$. mansoni infection in the WT. Instead, IFNy production was significantly increased, suggesting ITK deficiency skewed TCR response towards Th1 differentiation. Paradoxically, the same investigations in the Itk-/-Rlk-/- double knock out mouse (expected to be impaired more severely) did not show any weaker response compared to WT. Another agent to induce a powerful Th2 response is the challenge with the nematode Nippostrongylos brasiliens [33]. 12 days after infection with $\mathrm{N}$. brasiliensis wild type $\mathrm{BALB} / \mathrm{c}$ mice had cleared the worm infection in the gut; in contrast BALB/c mice were unable to expel adult worms and showed a reduction of IL-4 producing cells. Remarkably, Itk-/- mice show low susceptibility to some intracellular protozoa [33]. BALB/c mice fail to clear infection with Leishmania major, as the usual Th2 response is incapable to clear the parasites; however $I t k-/-$ mice show an increase of Th1 dependent IFNy response, leading to the control of infection. The role of Toxoplasma gondii, which is usually considered to promote Th1 mediated-immunity, needs to be further elaborated, as Itk $-/-$ mice do succumb to this infection [37]. To our knowledge, reports in which $I t k-1-$ mice were challenged with the murine herpesvirus 68 (MHV-68), the closest infectious model resembling human EBV infection, have not been published yet. This is somehow surprising given the similarities between MVH-68 and EBV, which were reviewed elsewhere [38-40].

A further approach to examine the $\mathrm{Th} 1 / \mathrm{Th} 2$ differentiation was undertaken by several groups investigating the $T$ cell dependent airway hyperresponsiveness in $I t k-/-$ mice.

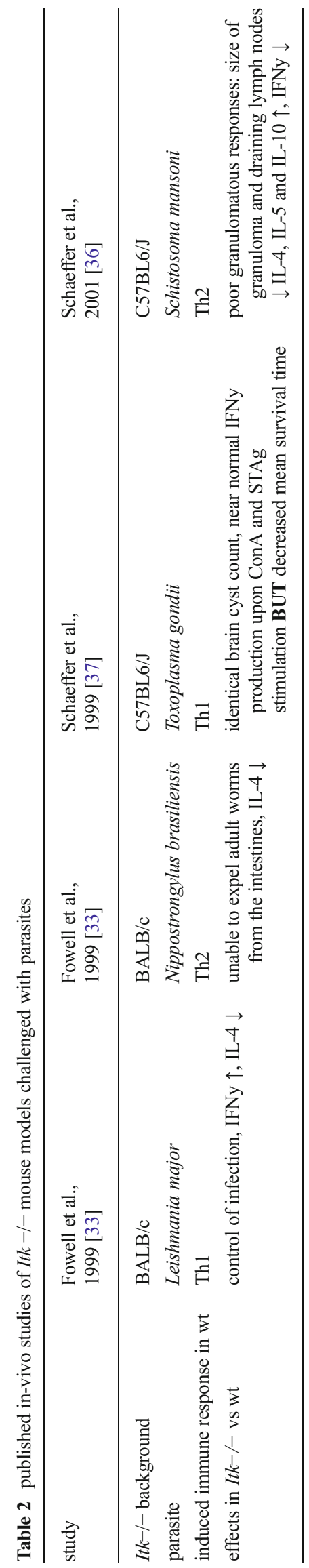


Asthma is characterized by the infiltration of Th 2 cells into the lungs; Itk -/- mice have reduced airway hyperresponsiveness to allergen challenge most likely due to an impaired Th2 response [41]. In humans, only epidemiological studies have focused on SNPs in the ITK gene and the susceptibility to developing asthma without any further functional validation [42].

Comprehensive studies beyond the Th1/Th2 paradigm were published by Gomez-Rodriguez 2009 and 2014 [43, 44]. The main focus was the differentiation of Th17 and Treg cells in Itk-/- mice. Under Th17 polarizing conditions sorted CD4 cells expressed significantly less IL17A and more FoxP3 RNA compared with wild type cells confirmed by intracellular staining. Moreover, under Treg culture conditions, a larger amount of cells of Itk -/- naïve CD4 cells progressed to FoxP3 compared to wild type CD4 cells. Unfortunately, in ITK deficient patients the Th17 and Treg development and function have not been studied yet. The authors further describe a reduced TCR-induced phosphorylation of mammalian target of rapamycin (mTOR) targets accompanied by an altered downstream metabolic profile.

A recent study investigated the protective effect of ITK deficiency on autoimmune phenomena. CTLA-4 has a quite important function in maintaining $\mathrm{T}$ cell tolerance to self, thus Ctla 4 - $/$ mice die of an autoimmune lymphoproliferative disorder driven by self-reactive $\mathrm{T}$ cell activation and tissue infiltration [45]. In contrast, the Ctla4-/- Itk-/- double knockout mouse lacks autoimmune pathology and shows a significant reduced lethality.

\section{ITK Inhibition}

The application of pharmacological ITK inhibitors significantly increased the lifespan of the above mentioned double knockout mouse. The authors further investigated ITK function in the non-obese diabetic mice (NOD), the mouse model of autoimmune insulin-dependent diabetes mellitus, which usually leads to complete destruction of pancreatic beta islets. ITK inhibition by pharmacological means was able to prevent the disease. In contrast to EBV, several viral infections like HIV, Influenza A and Coxsackie virus seem to have a replication cycle depending on ITK [46-48]. Inhibition of ITK leads to inhibition of the replication and alleviation of symptoms in the disease-model. These and many further studies of pharmacological inhibition, often developed from known BTK inhibitors, will portray ITK deficiency from a different perspective. Enthusiastic investigations undertaken to achieve a selective Th1 response is "sought by the medical community given their potential to inhibit a number of Th2-dominant autoimmune, inflammatory, and infectious diseases ranging from cancer immunosuppression and atopic dermatitis to inflammatory bowel disease and even HIV/AIDS" [49, 50].
However to conclude human ITK physiology and primary ITK immunodeficiency from these inhibitors is quite ambiguous as this model reflects the acquired rather than the inherited innate ITK impairment.

\section{Mast Cell Physiology and NK Cell Mediated Cytotoxicity Depends on ITK Function}

Given the restricted expression of ITK in T-cells and mast cells, the functional properties of mast cells lacking ITK have been tested in mouse. ITK has been attributed to differentially modulate mast cell degranulation and cytokine production by regulating expression and activation of NFAT proteins. However, the interactions of an allergen-induced mast cell response, serum IgE and histamine release and consecutive altered expression of the FceR are the main features of mast cell dysfunction in the Itk-/- mouse [51].

To the best of our knowledge only one study addressed an altered NK function due to ITK impairment. In a human NK cell model, ITK function was inhibited by the application of siRNA; the authors show, that in activated human NK cells, ITK differentially regulates distinct $\mathrm{NK}$-activating receptors. They suggest that ITK positively regulates FcR-initiated cytotoxicity, while in contrast, enhanced ITK expression would negatively regulate NKG2D-initiated granule-mediated killing [52].

\section{Summary}

Over the last 5 years, a couple of patients suffering from inherited ITK deficiency have been reported and it is quite likely that many more have to be identified. After infection with EBV, their clinical symptoms - usually accompanied by ultra-high EBV viral load in the peripheral blood - develop, namely severe lymphoproliferation, and Hodgkin's lymphoma. The frequent pulmonary involvement seems to emerge as one clinical hallmark, which should alert clinical immunologists to ITK. To date, it remains unknown if there is a major pathology in EBV-negative patients as all reported children with LPD were diagnosed after their first encounter with EBV. Definitive treatment recommendations cannot be given yet, but the current knowledge suggests that early stem cell transplantation is life saving. B cell depletion, e.g. by anti-CD20 therapy seem to be only temporary beneficial for those patients.

Both, the physiological role of ITK in mouse models and the functional consequences of the loss-of function mutations identified in human patients have been comprehensively studied. While the murine model has been challenged with various parasites to study Th1 and Th2 responses, an "EBV-mimicking" MHV-68 infectious model is warranted to reveal the 
pathogenesis of EBV infection in ITK deficiency. Furthermore, a more detailed developmental and functional characterization of T-cell subsets (Tregs and Th17 cells) and mast cells lacking ITK will be challenging issues in further studies.

Open Access This article is distributed under the terms of the Creative Commons Attribution License which permits any use, distribution, and reproduction in any medium, provided the original author(s) and the source are credited.

\section{References}

1. Parvaneh N, Filipovich AH, Borkhardt A. Primary immunodeficiencies predisposed to Epstein-Barr virus-driven haematological diseases. Br J Haematol. 2013;162(5):573-86. PubMed PMID: 23758097.

2. Felgentreff K, Perez-Becker R, Speckmann C, Schwarz K, Kalwak $\mathrm{K}$, Markelj G, et al. Clinical and immunological manifestations of patients with atypical severe combined immunodeficiency. Clin Immunol. 2011;141(1):73-82. PubMed PMID: 21664875.

3. Gholam C, Grigoriadou S, Gilmour KC, Gaspar HB. Familial haemophagocytic lymphohistiocytosis: advances in the genetic basis, diagnosis and management. Clin Exp Immunol. 2011;163(3):27183. PubMed PMID: 21303357. Pubmed Central PMCID: 3048610.

4. Risma K, Jordan MB. Hemophagocytic lymphohistiocytosis: updates and evolving concepts. Curr Opin Pediatr. 2012;24(1):9-15. PubMed PMID: 22189397.

5. Gaspar HB, Sharifi R, Gilmour KC, Thrasher AJ. X-linked lymphoproliferative disease: clinical, diagnostic and molecular perspective. Br J Haematol. 2002;119(3):585-95. PubMed PMID: 12437631.

6. Speckmann C, Lehmberg K, Albert MH, Damgaard RB, Fritsch M, Gyrd-Hansen M, et al. X-linked inhibitor of apoptosis (XIAP) deficiency: the spectrum of presenting manifestations beyond hemophagocytic lymphohistiocytosis. Clin Immunol. 2013;149(1): 133-41. PubMed PMID: 23973892.

7. Abdollahpour H, Appaswamy G, Kotlarz D, Diestelhorst J, Beier R, Schaffer AA, et al. The phenotype of human STK4 deficiency. Blood. 2012;119(15):3450-7. PubMed PMID: 22294732. Pubmed Central PMCID: 3325036.

8. Li FY, Chaigne-Delalande B, Su H, Uzel G, Matthews H, Lenardo MJ. XMEN disease: a new primary immunodeficiency affecting $\mathrm{Mg} 2+$ regulation of immunity against Epstein-Barr virus. Blood. 2014;123(14):2148-52. PubMed PMID: 24550228. Pubmed Central PMCID: 3975255.

9. Moshous D, Martin E, Carpentier W, Lim A, Callebaut I, Canioni D, et al. Whole-exome sequencing identifies Coronin-1A deficiency in 3 siblings with immunodeficiency and EBV-associated B-cell lymphoproliferation. J Allergy Clin Immunol. 2013;131(6):1594-603. PubMed PMID: 23522482. Pubmed Central PMCID: 3824285.

10. Salzer E, Daschkey S, Choo S, Gombert M, Santos-Valente E, Ginzel $\mathrm{S}$, et al. Combined immunodeficiency with life-threatening EBVassociated lymphoproliferative disorder in patients lacking functional CD27. Haematologica. 2013;98(3):473-8. PubMed PMID: 22801960. Pubmed Central PMCID: 3659923.

11. van Montfrans JM, Hoepelman AI, Otto S, van Gijn M, van de Corput L, de Weger RA, et al. CD27 deficiency is associated with combined immunodeficiency and persistent symptomatic EBV viremia. J Allergy Clin Immunol. 2012;129(3):787-93 e6. PubMed PMID: 22197273. Pubmed Central PMCID: 3294016.

12. Huck K, Feyen O, Niehues T, Ruschendorf F, Hubner N, Laws HJ, et al. Girls homozygous for an IL-2-inducible T cell kinase mutation that leads to protein deficiency develop fatal EBV-associated lymphoproliferation. J Clin Invest. 2009;119(5):1350-8. PubMed PMID: 19425169. Pubmed Central PMCID: 2673872.

13. Linka RM, Risse SL, Bienemann K, Werner M, Linka Y, Krux $\mathrm{F}$, et al. Loss-of-function mutations within the IL-2 inducible kinase ITK in patients with EBV-associated lymphoproliferative diseases. Leukemia. 2012;26(5):963-71. PubMed PMID: 22289921.

14. Mansouri D, Mahdaviani SA, Khalilzadeh S, Mohajerani SA, Hasanzad M, Sadr S, et al. IL-2-inducible T-cell kinase deficiency with pulmonary manifestations due to disseminated Epstein-Barr virus infection. Int Arch Allergy Immunol. 2012;158(4):418-22. PubMed PMID: 22487848.

15. Stepensky P, Weintraub M, Yanir A, Revel-Vilk S, Krux F, Huck K, et al. IL-2-inducible T-cell kinase deficiency: clinical presentation and therapeutic approach. Haematologica. 2011;96(3):472-6. PubMed PMID: 21109689. Pubmed Central PMCID: 3046282.

16. Serwas NK, Cagdas D, Ban SA, Bienemann K, Salzer E, Tezcan I, et al. Identification of ITK deficiency as a novel genetic cause of idiopathic CD4+ T-cell lymphopenia. Blood. 2014;124(4):655-7. PubMed PMID: 25061172. Pubmed Central PMCID: 4110665.

17. Bienemann K, Iouannidou K, Schoenberg K, Krux F, Reuther S, Feyen $\mathrm{O}$, et al. iNKT cell frequency in peripheral blood of Caucasian children and adolescent: the absolute iNKT cell count is stable from birth to adulthood. Scand J Immunol. 2011;74(4):406-11. PubMed PMID: 21671972.

18. Qi Q, Kannan AK, August A. Tec family kinases: Itk signaling and the development of NKT alphabeta and gammadelta T cells. FEBS J. 2011;278(12):1970-9. PubMed PMID: 21362141.

19. Chung BK, Tsai K, Allan LL, Zheng DJ, Nie JC, Biggs CM, et al. Innate immune control of EBV-infected $\mathrm{B}$ cells by invariant natural killer T cells. Blood. 2013;122(15):2600-8. PubMed PMID: 23974196.

20. Heslop HE. How I, treat EBV lymphoproliferation. Blood. 2009;114(19):4002-8. PubMed PMID: 19724053. Pubmed Central PMCID: 2774540

21. Horwood NJ, Urbaniak AM, Danks L. Tec family kinases in inflammation and disease. Int Rev Immunol. 2012;31(2):87-103. PubMed PMID: 22449071

22. Bruton OC. Agammaglobulinemia. Pediatrics. 1952;9(6):722-8. PubMed PMID: 14929630

23. Vetrie D, Vorechovsky I, Sideras P, Holland J, Davies A, Flinter F, et al. The gene involved in X-linked agammaglobulinaemia is a member of the src family of protein-tyrosine kinases. Nature. 1993;361(6409):226-33. PubMed PMID: 8380905.

24. Hussain A, Yu L, Faryal R, Mohammad DK, Mohamed AJ, Smith CI. TEC family kinases in health and disease-loss-of-function of BTK and ITK and the gain-of-function fusions ITK-SYK and BTK-SYK. FEBS J. 2011;278(12):2001-10. PubMed PMID: 21518255

25. Kosaka Y, Felices M, Berg LJ. Itk and Th2 responses: action but no reaction. Trends Immunol. 2006;27(10):453-60. PubMed PMID: 16931156.

26. Readinger JA, Mueller KL, Venegas AM, Horai R, Schwartzberg PL. Tec kinases regulate T-lymphocyte development and function: new insights into the roles of Itk and Rlk/Txk. Immunol Rev. 2009;228(1): 93-114. PubMed PMID: 19290923. Pubmed Central PMCID: 2673963.

27. Atherly LO, Lucas JA, Felices M, Yin CC, Reiner SL, Berg LJ. The Tec family tyrosine kinases Itk and Rlk regulate the development of conventional CD8+ T cells. Immunity. 2006;25(1):79-91. PubMed PMID: 16860759 .

28. Blomberg KE, Boucheron N, Lindvall JM, Yu L, Raberger J, Berglof $\mathrm{A}$, et al. Transcriptional signatures of Itk-deficient CD3+, CD4+ and CD8+ T-cells. BMC Genomics. 2009;10:233. PubMed PMID: 19450280. Pubmed Central PMCID: 2689280. 
29. Broussard C, Fleischacker C, Horai R, Chetana M, Venegas AM, Sharp LL, et al. Altered development of CD8+ T cell lineages in mice deficient for the Tec kinases Itk and Rlk. Immunity. 2006;25(1):93104. PubMed PMID: 16860760.

30. Dubois S, Waldmann TA, Muller JR. ITK and IL-15 support two distinct subsets of CD8+ T cells. Proc Natl Acad Sci U S A. 2006;103(32):12075-80. PubMed PMID: 16880398. Pubmed Central PMCID: 1567699.

31. Nayar R, Enos M, Prince A, Shin H, Hemmers S, Jiang JK, et al. TCR signaling via Tec kinase ITK and interferon regulatory factor 4 (IRF4) regulates CD8+ T-cell differentiation. Proc Natl Acad Sci U S A. 2012;109(41):E2794-802. PubMed PMID: 23011795. Pubmed Central PMCID: 3478592.

32. Felices M, Berg LJ. The Tec kinases Itk and Rlk regulate NKT cell maturation, cytokine production, and survival. J Immunol. 2008;180(5):3007-18. PubMed PMID: 18292523.

33. Fowell DJ, Shinkai K, Liao XC, Beebe AM, Coffman RL, Littman DR, et al. Impaired NFATc translocation and failure of Th2 development in Itk-deficient CD4+ T cells. Immunity. 1999;11(4):399-409. PubMed PMID: 10549622.

34. Berg LJ, Finkelstein LD, Lucas JA, Schwartzberg PL. Tec family kinases in T lymphocyte development and function. Annu Rev Immunol. 2005;23:549-600. PubMed PMID: 15771581. Epub 2005/03/18. eng.

35. Schwartzberg PL, Finkelstein LD, Readinger JA. TEC-family kinases: regulators of T-helper-cell differentiation. Nat Rev Immunol. 2005;5(4):284-95. PubMed PMID: 15803148. Epub 2005/04/02. eng.

36. Schaeffer EM, Yap GS, Lewis CM, Czar MJ, McVicar DW, Cheever $\mathrm{AW}$, et al. Mutation of Tec family kinases alters $\mathrm{T}$ helper cell differentiation. Nat Immunol. 2001;2(12):1183-8. PubMed PMID: 11702066

37. Schaeffer EM, Debnath J, Yap G, McVicar D, Liao XC, Littman DR, et al. Requirement for Tec kinases Rlk and Itk in T cell receptor signaling and immunity. Science. 1999;284(5414):638-41. PubMed PMID: 10213685.

38. Cipkova-Jarcuskova J, Chalupkova A, Hrabovska Z, Wagnerova M, Mistrikova J. Biological and pathogenetic characterization of different isolates of murine gammaherpesvirus 68 (MHV-68) in the context of study of human oncogenic gammaherpesviruses. Acta Virol. 2013;57(2):105-12. PubMed PMID: 23600868.

39. Stevenson PG, Efstathiou S. Immune mechanisms in murine gammaherpesvirus-68 infection. Viral Immunol. 2005;18(3):44556. PubMed PMID: 16212523.

40. Rajcani J, Kudelova M. Gamma herpesviruses: pathogenesis of infection and cell signaling. Folia Microbiol. 2003;48(3):291-318. PubMed PMID: 12879740.

41. Kannan AK, Sahu N, Mohanan S, Mohinta S, August A. IL-2inducible T-cell kinase modulates TH2-mediated allergic airway inflammation by suppressing IFN-gamma in naive CD4+ T cells. $\mathrm{J}$ Allergy Clin Immunol. 2013;132(4):811-20. e1-5. PubMed PMID: 23768572.

42. Lee SH, Chang HS, Jang AS, Park SW, Park JS, Uh ST, et al. The association of a single-nucleotide polymorphism of the IL-2 inducible T-cell kinase gene with asthma. Ann Hum Genet. 2011;75(3): 359-69. PubMed PMID: 21323647.

43. Gomez-Rodriguez J, Sahu N, Handon R, Davidson TS, Anderson SM, Kirby MR, et al. Differential expression of interleukin-17A and $17 \mathrm{~F}$ is coupled to $\mathrm{T}$ cell receptor signaling via inducible $\mathrm{T}$ cell kinase. Immunity. 2009;31(4):587-97. PubMed PMID: 19818650. PubMed PMID: 19818650.

44. Gomez-Rodriguez J, Wohlfert EA, Handon R, Meylan F, Wu JZ, Anderson SM, et al. Itk-mediated integration of $\mathrm{T}$ cell receptor and cytokine signaling regulates the balance between Th17 and regulatory T cells. J Exp Med. 2014;211(3):529-43. PubMed PMID: 24534190. Pubmed Central PMCID: 3949578.

45. Jain N, Miu B, Jiang JK, McKinstry KK, Prince A, Swain SL, et al. CD28 and ITK signals regulate autoreactive T cell trafficking. Nat Med. 2013;19(12):1632-7. PubMed PMID: 24270545.

46. Fan K, Jia Y, Wang S, Li H, Wu D, Wang G, et al. Role of Itk signalling in the interaction between influenza A virus and T-cells. J Gen Virol. 2012;93(Pt 5):987-97. PubMed PMID: 22302878.

47. Hennig C, Ilginus C, Boztug K, Skokowa J, Marodi L, Szaflarska A, et al. High-content cytometry and transcriptomic biomarker profiling of human B-cell activation. J Allergy Clin Immunol. 2014;133(1): 172-80. e1-10. PubMed PMID: 24012209.

48. Readinger JA, Schiralli GM, Jiang JK, Thomas CJ, August A, Henderson AJ, et al. Selective targeting of ITK blocks multiple steps of HIV replication. Proc Natl Acad Sci U S A. 2008;105(18):6684-9. PubMed PMID: 18443296. Pubmed Central PMCID: 2365562.

49. Dubovsky JA, Beckwith KA, Natarajan G, Woyach JA, Jaglowski S, Zhong Y, et al. Ibrutinib is an irreversible molecular inhibitor of ITK driving a Th1-selective pressure in T lymphocytes. Blood. 2013;122(15):2539-49. PubMed PMID: 23886836. Pubmed Central PMCID: 3795457.

50. Vargas L, Hamasy A, Nore BF, Smith CI. Inhibitors of BTK and ITK: state of the new drugs for cancer, autoimmunity and inflammatory diseases. Scand J Immunol. 2013;78(2):130-9. PubMed PMID: 23672610 .

51. Iyer AS, August A. The Tec family kinase, IL-2-inducible T cell kinase, differentially controls mast cell responses. J Immunol. 2008;180(12):7869-77. PubMed PMID: 18523250. Pubmed Central PMCID: 2583454.

52. Khurana D, Arneson LN, Schoon RA, Dick CJ, Leibson PJ. Differential regulation of human NK cell-mediated cytotoxicity by the tyrosine kinase Itk. J Immunol. 2007;178(6):3575-82. PubMed PMID: 17339454. 